\title{
Methods of Creating Creativity through De-familiarization Technique and the Role of the Audience in Interactive Graphics
}

\author{
Razieh Mokhtari Dehkordi ${ }^{1}$, Azam Atapour ${ }^{2}$ \\ ${ }^{1}$ Assistant Professor of Visual Communication, Faculty of Arts and Humanities, Shahrekord University, \\ Shahrekord, Iran \\ ${ }^{2}$ Art Teacher of Education Organization, Zarch, Yazd, Iran \\ mokhtari_razieh@yahoo.com
}

\section{Abstract}

The theory of de-familiarization was first introduced in the field of literature and later due to its consistency and maturity, it was also studied in other fields and branches of art. The basis of interactive graphics is based on inviting the audience in the process of forming the work, and the de-familiarization technique can provide a platform for more creativity and interaction. The purpose of this study is to identify ways to create creativity through de-familiarization techniques and the role of the audience in interactive graphics. The question of what interactive graphics is and why they are formed is one of the issues that this research seeks to address. The main question of this article is how interactive graphics can create creative works to attract the audience through the familiarization technique? To achieve the desired goals, a qualitative research method with a descriptive-analytical nature was adopted and the studied works, which were collected through library resources, were analyzed by qualitative content analysis. The results showed that interactive graphic designers can create more creative and interactive works in the field of graphics through various methods of de-familiarization.
Keywords

de-familiarization technique; role of the audience; interactive graphics

\section{Introduction}

In a world where visual communication is a big part of people's daily lives, drawing the audience's attention to the message requires specialized knowledge, because people pay attention to something that they are curious about. One of the tricks that can be used to achieve this goal is familiarization. Defamiliarization is one of the most obvious creative methods in graphics. This approach transforms our visual habits that have developed over time and causes surprise in the audience and by disrupting the audience's meeting habits and visual perceptions, it creates a sense of wonder in him and he is eager to see and participate in the relationship. This research aims to show the ways of creating creativity through de- familiarization techniques in interactive graphic design.

\section{Review of Literature}

\subsection{The Concept of De-Familiarization}

«One of the most important points that formalists pay attention to the form of expression is the concept of unfamiliarity. "Viktor Shklovsky" first introduced this concept with the Russian word Ostrannenja. After him, "Roman Jakobson" and "Yury Tynyanov" in some cases referred to this concept as "alienation" (Ahmadi, 2003: 47) ». Our understanding of the concept of phenomena and our sense of their beauty is undoubtedly 
SIASAT Journal of Social, Cultural and Political Studies, 6 (4) October 2021, 178-189

ISSN: 2721-7469 (Print), 2721-7450 (Online)

Razieh Mokhtari Dehkordi, Azam Atapour: Methods of Creating Creativity through Defamiliarization Technique and the Role of the Audience in Interactive Graphics

https://siasatjournal.com/index.php/siasat

an approach that gradually takes the form of habit. According to Shkolovsky, a large part of our lives is based on these habits. That is, the habit of beings, objects, and the environment around us forces us not to see them. In the first encounter with an object or being, we are unfamiliar with it. Gradually we become accustomed to it through observation and little by little we no longer see it. In other words, in everyday life, we do many things automatically and without thinking or reflection. What we do not consciously see and see automatically does not exist for us. There are only things for us that we see consciously, we pause about them and we value them and according to "Nafisi" belief, we are constantly discovering and experiencing them (Nafisi, 2007: 36).

The normalization of our view of phenomena causes us to ignore their true nature and suffice with a superficial knowledge of them. The need to change the visual attitude starts from this point, so that the need to break familiar rules and norms in order to create a new look at the process of artistic creation is felt. This is where the artist discovers the unseen, the unfamiliar, and the new world, and sometimes, knowingly or unknowingly, uses the techniques of an approach known as " De-Familiarization". Shkolovsky's first reference to the De-Familiarization can be found in his treatise "Art as Technique" (1917). In his view, art reorganizes our sensory perception, and in this way transforms familiar rules and the introduction of seemingly enduring structures of reality. According to Ahmadi, art changes our habits and makes everything familiar to our eyes. It alienates (Ahmadi, 2003: 47).

In fact, it can be said that De-Familiarization is the most important way to distinguish works of art from other human creations. Shkolovsky believes that the task of art is essentially to make things unfamiliar, or in other words, to complicate things and take them away from the realm of habit and everyday life. In the light of the concept of unfamiliarity, he offers an important view of works of art that does not recognize the problem of art and believes that art cannot achieve knowledge (science) of objects, which is the work of scientific language and not poetic expression. He says, "The function of poetry or art is not to acquaint the audience with unfamiliar concepts, but on the contrary, to acquaint the same familiar objects that have surrounded us" (Abedinifard, 2009: 83).

\subsection{Interactive Art}

Interactive art is a branch of modern art that is based on inviting the audience in the process of forming the work, a special kind in which the basis of creating a work of art is the interaction and communication between the audience and the work of art. Interactive art is an art with its own structures, a form independent of other types of interactionoriented arts. Interactive art, on the one hand, reveals its independent existence of similar species by using the interaction of the audience to interpret the play, and on the other hand, by insisting on the active action of the audience in changing this play. A work of art is only interactive if it imagines that it is the actions of its users that help create its display. The physical and real action of the audience in interactive art, which leads to a change in the performance of the work, is the most important feature of this type of art. Because the work is essentially interaction-oriented, the full reception of the work depends on interacting with it and changing the display of the work. The audience will engage with the work physically and actively through the mediation of enclosed computer interfaces. In interactive art, the active and creative participation of the audience has caused the art to be taken out of the exclusive ownership of the author or creator of the work. In other words, interactive art is the way in which the audience can participate in the work, communicate and influence it, and even make changes to it at will. In interactive art, in order to communicate more with the message, the audience participates in creating the work and 
sometimes replaces the audience with the artist. In this art, far from de-conceptualization, the audience discovers and reconstructs a concept, and during the interaction with the work, thinking about the subject and proposing new perspectives are formed. Designing cultural, political, social issues, focusing on the concept, interacting with the audience, using cyberspace and technological implementation are the characteristics of this art.

\subsection{Interaction and Environmental Art}

Environmental art is such that it crosses the traditional boundary between the audience and the work of art and blends them. This combination of environmental art works with its audience is one of the important aspects of this art, which leads to strengthening the relationship between the work and the audience. Environmental art is always based on engaging the audience with the work of art and requires the participation of the audience to be complete. It is a combination of art that the artist creates in a conscious process using elements, in a way that engages the audience, placing them in a set of visual, auditory and visual motivations (Azemati, 1393). Existence of environmental art interactively can strengthen the sense of belonging to the environment and its natural and living places by stimulating and influencing the mental perception of the audience and be a factor for human connection with the environment and nature. Audience participation, in addition to creating interaction between the user and the environment, creates meaning for the audience and influences their way of life by creating a desirable feeling. Having an interactive experience for a person with a particular place can depend on the strength of the relationship and how meaningful the experience is. The stronger the relationship, the more important the experience will be. Environmental art can make connections according to external, social and cultural conditions and provide cultural promotion as well as the promotion of public education in society. When using interaction in environmental art, it should be noted that in such a case, this art can increase its pervasiveness and make it a mass and artistic medium by using communication and creating attraction for the audience. Which has educational goals to play a role.

\subsection{Interactive Graphics}

Interactive graphics is a branch of graphic science that borrows from interactive art and offers new products with new features. Advertising is one of the most important branches of graphics in which the discussion of interaction is used. Interactive artists produce their work with different tendencies, but the common goal of all of them is to engage as much as possible with the work, to be in the text and to change it. The questions that arise for the viewer during the interaction with the work, make him think about the subject of the work and perhaps offer him new perspectives.

\section{Results and Discussion}

\subsection{Defamiliarization Techniques in Interactive Graphics}

Given that De-Familiarization provided a suitable platform for the artist to convey to the audience his visual experiences of the relationships between objects and the mental concepts associated with them, to give a different understanding of the objects and things on which the color of human habit sat. Man gave the present age. In fact, with the help of special cryptography, a completely personal world was created. A world not so familiar with minds addicted to familiar images that you are trying to change the audience's perception of the world. It was possible to make these visual changes in order to get used 
to meeting with different methods and techniques, the tricks of which can be classified into the following formats:

a. Displacement that involves changing the viewing angle, location, function, size, color, as well as placing one image in place of another.

b. Invert or reverse

c. Exaggeration in displaying product performance

d. Combining and putting images together

e. Using visual arrays including: metaphor, ambiguity, paradox, irony and symbol

\section{a. Displacement}

Moving events or relationships so that each can take a different place is an important process in the visualization of advertising, which, according to Osulivan, the elements of the product in question and the image created for the product in the ad are virtually shifted. Osulivan et al., 2006: 409).

Displacement can occur in the following cases:

1. Changing the angle of view: When the angle of view changes in simple and trivial subjects, the result of the work becomes an interesting and noteworthy subject. This is an effective way to unleash creativity and increase the reader's attention. "This method is possible in two ways: one is to see the subject from an unusual angle or the angle of view of the fish using fisheye lenses, or exaggerated large-scale images" (Afshar Mohajer, 2009: 613) (Figure 1).

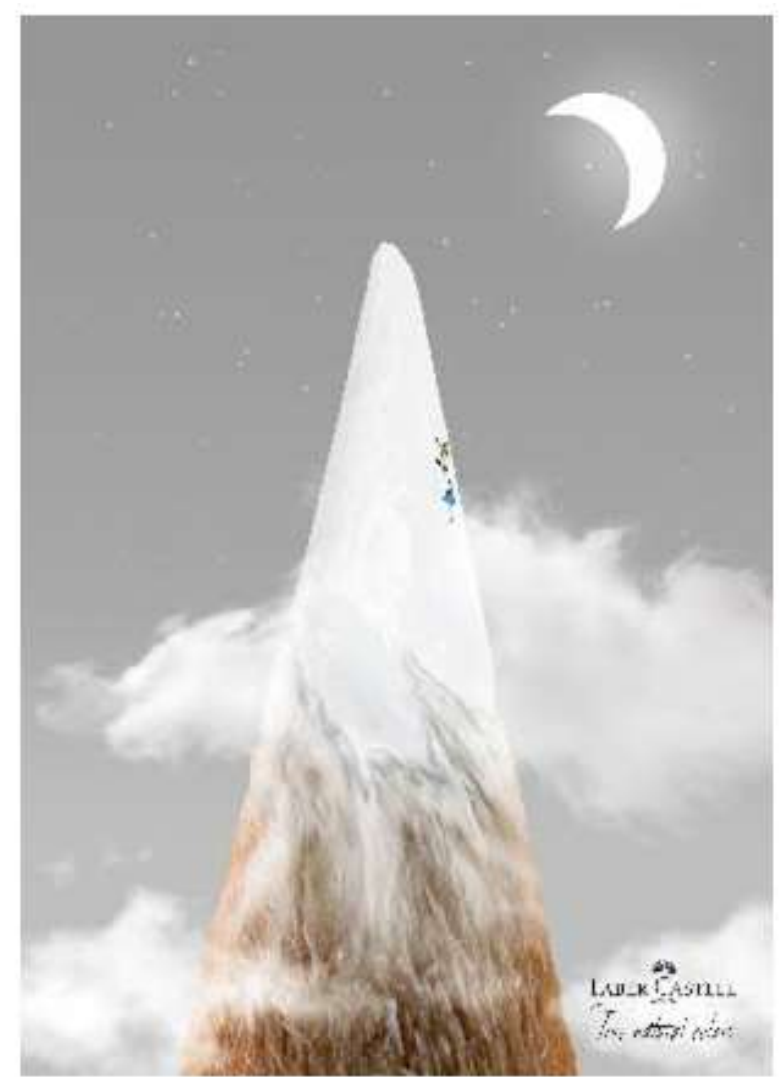

Figure 1. Print advertisement created by Miami Ad School, Germany for Faber Castell

(https:/www adsoftheworld com/media/print/fa ber_castell_mountain) 
2. Relocation: Another form of relocation initiative. According to Monari: "A person lying in his bed is not surprised if he is in his room, but if in the middle of the town church with a bed, a small table and a clock, a rug under the bed and slippers lying

3. in the middle of the passage and passers-by to be observed, In this case, someone may pay attention to him "(Monari, 1381: 103) (Figure 2).

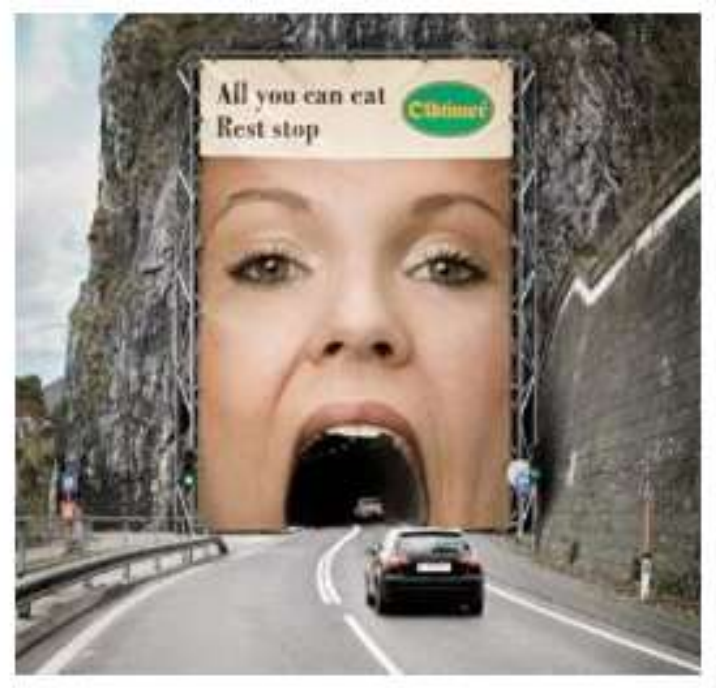

Figure 2. Oldtimer's mountainside rest stop ad, in Austria

(https:/www. wordstream.com/blog/ws/ 2012/02/08/seven-innovative-ads)

4. Change of function: It is when we select something that has a certain function and use it to do something else. Like a glass instead of a vase, a bottle instead of the base of a light bulb (Figure 3).

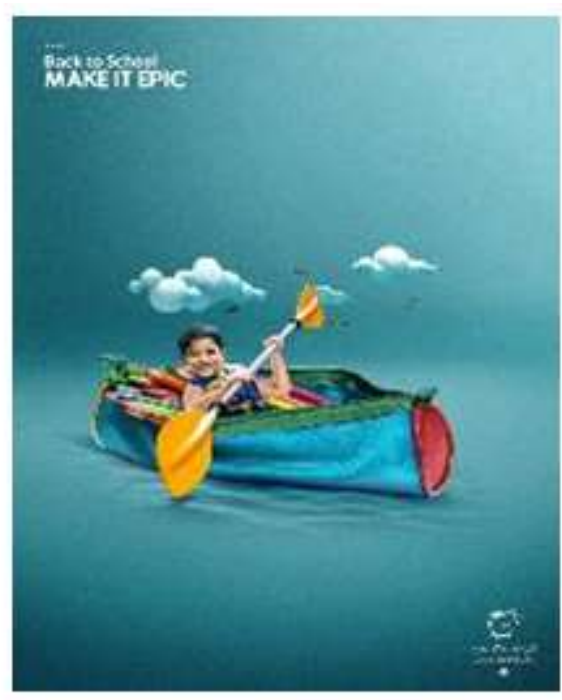

Figure 3. Performance change (https./taskshift.com/aartikumari/offer/i -will-design-creative-poster/) 
5. Changing in size and color: Zooming in or out of natural shapes disrupts the organization of people's minds, and this in itself attracts more and more attention. Also, by making a change in the color of the phenomena, the audience's mind can be disturbed.

6. Placing one image instead of another: In this method, it means that in order to attract attention and achieve a kind of creative excitement, an image can be used for a purpose that is not expected.

\section{b. Inversion}

The earliest manifestation of initiative may arise from reversing a use of anxiety, adversaries, and supplements. "In this method, by presenting the opposite of what people expect, the audience's attention is attracted and this attention is associated with the type of emotion that contributes to success in general" (Afshar Mohajer, 2009: 615). Reversing people has always had instructions normally, not only can I not come up with an interesting and creative idea, it is neither surprising nor surprising (Figure 4).

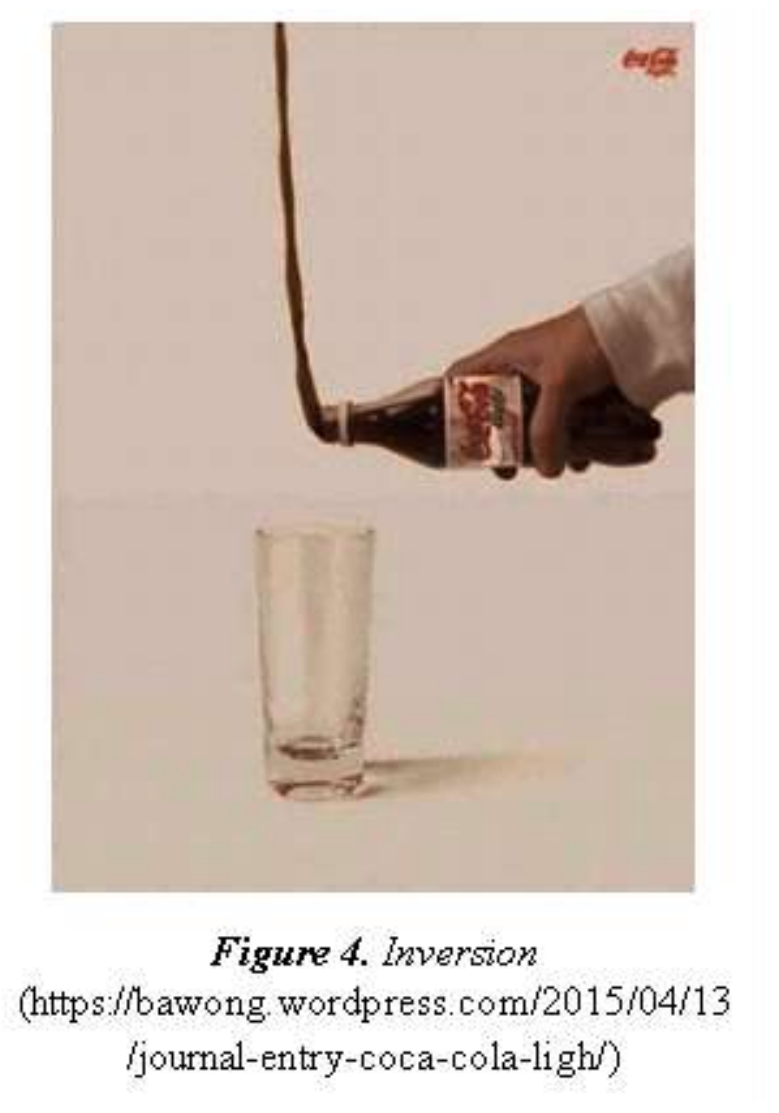

\section{c. Exaggeration in Product Performance}

"Exaggerating in showing the features and functions of a product and the new solutions offered in it can increase the audience's attention and show the importance and usefulness of the product." (Ejadi, 1383: 34) (Figure 5). 


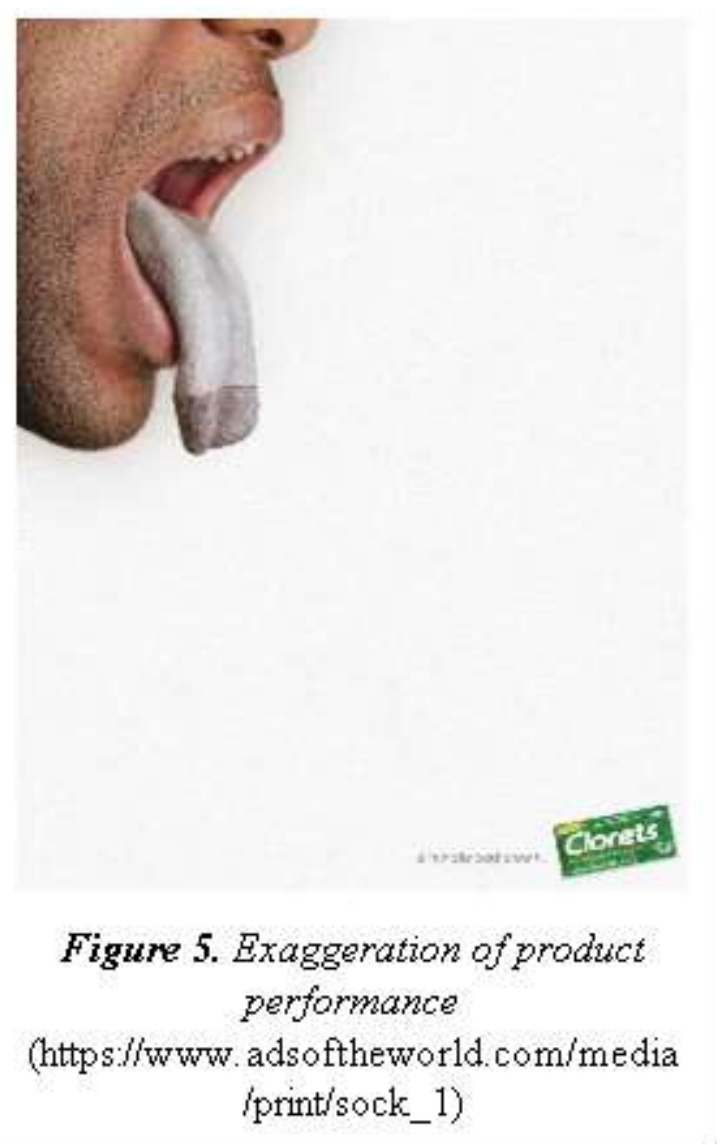

\section{d. Combining and Putting Together}

In this way, in presenting the target theme, it is possible to create an unusual relationship with the audience, which is one of the common tricks of designers to present and raise the topic. In this method, two topics are created together to create a new topic. The new concept and work are easily communicated and understood by the audience (Figure 6).

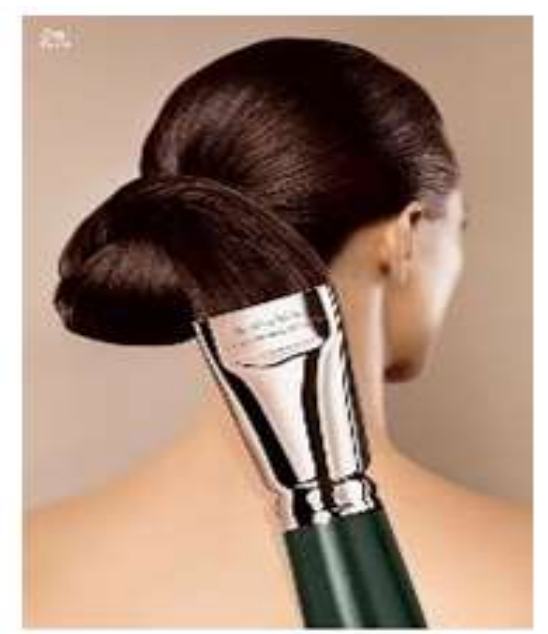

Figure 6. Combining and putting together

(https:/www. memecenter.c om/fun/21071/creative-adhair-brush) 


\section{e. Use Visual Arrays}

Arrays such as similes, metaphors, metaphors, and puns are not just for language, that is, they can be understood beyond our linguistic information. These categories seem to be highly human and innate before they can be literary or linguistic. The taste for discovering similarities and linking things that seem to be unrelated is present in the nature of all human beings" (Critchley, 2004: 9).

Therefore, in addition to literature, their field of application in visual messages can also be considered, which in the continuation of the discussion, their features in the field of visual are discussed.

1. The method of using ambiguity: «In this method, in addition to the apparent meaning, the audience is also presented with an internal meaning that causes the viewer to pause and stop the announcement» (Khodadad Hosseini, 1389: 168) (Figure 7).

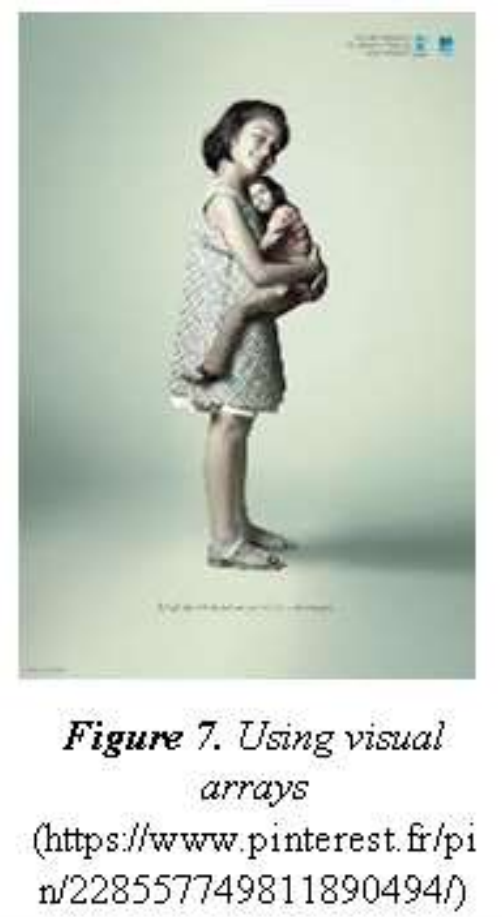

2. How to use metaphor: Metaphor is the most powerful tool for expressing different subjects (Afshar Mohajer, 2009: 606). «Slowly As it is stated in traditional studies, this is done on the basis of pseudo-aspect or dominant aspect or interest in similarity» (Sasani, 1390: 27). When we speak of metaphor, we connect two different ones. Although the two seem to be far apart, in practice they are able to express each other. Metaphors have a paradigmatic function. They place the unknown in the new paradigm from which part of the new meaning derives. Metaphor then requires the active and creative decipherment of the reader to figure out which features can be meaningfully displaced. Poets and advertisers try to demand the active involvement of the recipient. The first group hopes that decryption can provide a creative process that is consistent with encryption and the second group hopes to make the required cooperation of the recipient more sensitive to the claims of the product ("Osulivan et al., 2006: 244-245)

3. Use of irony: Irony implies all that by using a part or element of something. In fact, irony and metaphor are the two basic ways of transmitting meaning. The irony works on the axis of companionship, and the metaphor draws attention to itself by being artificial and by the imagination needed to decipher it. The irony seems so natural that it is taken for granted while having an invisible function. 
4. Use of paradox: The paradoxical picture is new and unusual. Our minds, being accustomed to the ordinary things and to the logic of nature, are immersed in the neglect of habit; We live our normal lives in the era of causal systems and we interpret all the phenomena of the world in accordance with our logic and the fixed laws of nature. The mind accustomed to such a habit, when it encounters an interpretation contrary to the habit, suddenly becomes agitated and awakens from negligence. The two contradictory sides in the paradoxical image are like two blades of scissors that bite the mind addicted to ordinary affairs (Fotouhi, 2007: 329).

5. How to use similes: A simile is a kind of metaphor in which both the known and the unknown are present. Commercial advertisements and metaphors are more like similes because they contain both the known and the unknown (Osulivan et al., 2006: 245). Describing a product is never as effective as proving its quality; The art of creative advertising is to place a product in a short period of time using the phenomenon of simile in the direction of a quality product that has gained its place among customers after years of use "(Khodadad Hosseini, 1389: 168) (Figure 8).

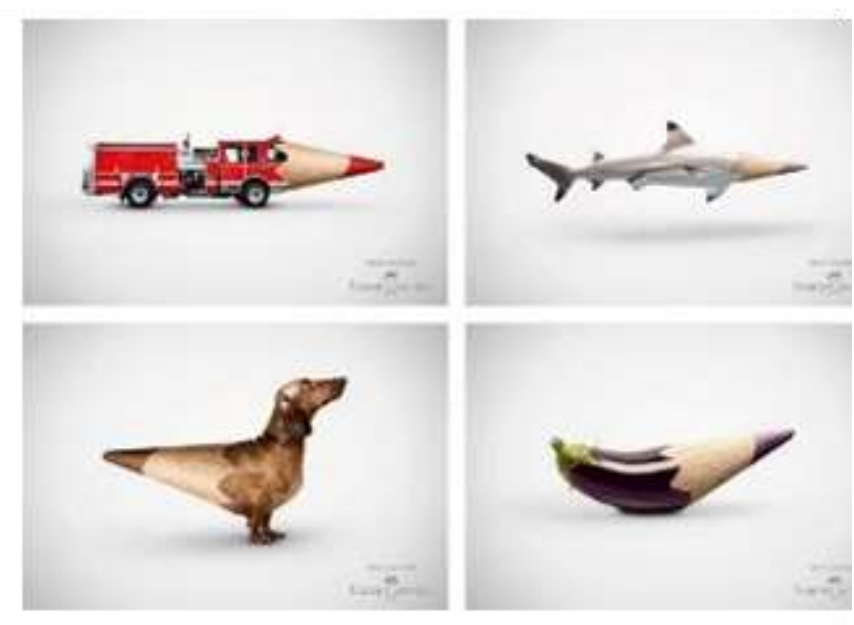

Figure 8. Using similes for Faber-Castell

products

(https:/www.pinterest.com/pin/487656084375

665920

6. How to use a symbol ": A symbol is something that is intentionally used to represent and replace something else" (Positive, 1389: 68). Virtual concepts, signs, and symbols are now the human need today to reach a level of communication in which speed is the first pillar. From the distant past, ideas and concepts that have been difficult to express, understand and describe have been presented in the form of systems of signs so that if many words are normally needed to describe a category, it can only be Draw in an image that has the face of a symbol or sign.

\subsection{Defamiliarization Techniques}

Art is an intellectual phenomenon and its objectification can be done using any kind of tool. The image is a kind of language and the effective use of various tools allows the designer to express his thoughts and feelings in this language. Therefore, more and more familiarity with the tools and their proper use increases the number of viewers who understand. "It is obvious that the use of a transcendent and appropriate technique by the 
subject matter, so that all truth is presented in an artistic form and the subject and content can emerge with an expression without exaggeration, shortcomings and darkness, is the goal of the artist" (Nowruzi Talab, 1989: 8).

New visual techniques have provided a good platform for the visual representation of creative, unfamiliar ideas. The presence of digital art in the present age with its many possibilities, contemporary designers have consulted and the process of image production and the ability to reproduce the work in high circulation and provides them with countless printing possibilities.

"In a broader perspective, digital art is a practical term for contemporary art that refers to a variety of processing and production methods with digital media" (Fereydoni, 2008: 307) in an article in Art Journal that deals with art and computer Margaret Loveju, Terry Gypsum and George Legrady have paid close attention to the importance of photography and its alignment with graphic elements as the basis of computer art (Popper, 2005: 231). This issue can be traced to He knew that many of the designers' ideas could be made possible by photography. In the expression of metaphor, which can be a very effective method in advertising, photography has a successful application. "Effective techniques such as photomontage help the designer to capture novel and bizarre scenes that are unlikely to occur in the real world." Photomontage is a composite image that combines parts of several (or all) different negative images It is created in such a way that the resulting image cannot be found in reality "(Rahimi, 1388: 130)

\subsection{Relationship between Creative Techniques and Familiarization}

The exponential growth of visual products has created a competitive environment for image producers due to the proliferation of visual media. Therefore, designers and illustrators have to put innovation on their agenda in order to surprise and attract the viewer due to being different and being noticed. Being creative means being able to create something new with a new value. Artistic arrangements in art have much in common with creative ideas. "The designer also uses de-familiarization strategies to create an image that did not exist before. A variety of combining and substituting methods are at the heart of many of today's creative activities, and numerous release strategies for developing and producing mental products are based on them. Synectic, for example, is a technique for enhancing creativity.

The word is derived from the Greek root "synetikos" meaning to push two things together or to connect several different things, because creativity is also a kind of coordination of different things in a new form or structure. This technique is a method to stimulate creative thinking in which analogy and metaphor are deliberately used in order to create new views and opinions "(Samad Aghaei, 2001, 141-142).

All of this is creative in order to achieve the desired concepts using a new form of expression. Also, the artist must consider the semantic connection between them in the proximity and fusion of images. An idea is an idea that is evoked by linking two concepts that are already unrelated to each other. Coexistence creates new patterns and new relationships and creates a new way of looking at things. This phenomenon has been described as the creation of the familiar unfamiliar and the unfamiliar familiar. A creative idea involves a mental change. Instead of seeing the obvious, a creative idea looks at it differently and from another angle" (Wells et al., 2004: 459).

\subsection{De-familiarization and the Role of the Audience in Creating Meaning}

Interactive graphics as a branch of graphics, has the most dependence on its audience and viewers because it should attract viewers, convey its message to them and finally the 
viewer's satisfaction from watching the work draws the view of both of them. To persuade to buy goods and services. "People are always interested in working together. Advertising thinker Jeremy Ballmore convincingly discusses the benefits of playing the audience: I think getting involved in a relationship is everything. "If I do everything as a sender, the only thing left for the recipient is to deny. Because the only thing you can do is oppose me" (Yahaghi, 1388: 369 - 370). "One of the main purposes for using the image in advertising activities is to create a reaction or, in its psychological interpretation, to provoke a response among the audience" (Masari, 2000: 87).

Involving the audience in the communication process increases the effectiveness of the message and plays an important role in convincing the audience. "The important concept that the formalists put forward, alienation or unfamiliarity, is a technique based on the perception and interpretation of the audience. In this technique, the important issue is to eliminate the familiar and ordinary perception so that the audience is not satisfied with their first sensory perception of the work through familiarity and unfamiliarity of language and expression, but to interpret it "(Ahmadi, 2009: 397).

In this method, instead of what the recipients of the message have experienced many times and are familiar with, the sender uses the signals in unexpected ways. As in the first step, recognizing the subject becomes impossible or very difficult. But the main goal is to know in new ways, not to deny the necessity of knowing. Art adds to the difficulties of sensory perception and makes the subject appear as if it were appearing for the first time. To the extent that the purpose of the image is no longer to bring meaning closer to the audience's cognition, but to create a new form of perception: to expand the possibility of knowing the audience. As with the creation of new images, the scope of interpretation will expand and new meanings will be created. Every word or image first has an explicit meaning and then an implicit, indirect and inferential dimension.

"In the case of illustrations or pictorial representations, the audience, by recognizing the similarity between the experience of that representation and some aspects of the experience of the represented object, determines what is represented" (Young, 2009: 48). "The perception and impression of the image for the viewer depends a lot on his previous experience and knowledge; therefore, the visual image is not a mere representation (reality) but is a symbolic system" (Afshar Mohajer, 2009: 540). But each system of signs makes sense according to several factors. The process of producing meaning in images is very dynamic and evolving. No image has a fixed meaning and takes on different meanings at different times, places, and societies, under the influence of various social, political, cultural, and historical factors. The key to achieving its meaning is to decipher pictorial contracts. Therefore, any image contract can be a code or even a symbol. But codes and symbols are fixed and unchangeable meanings and are interpreted from different aspects and each time they take on a new meaning. The key to decoding images is in interpreting the clues that the creator of the image, intentionally or unintentionally, or perhaps implicitly, was able to place in the image. These clues may be visual factors such as color, tone, contrast, composition, perspective, and type of style. Traditionally, the role of a graphic designer is to convey information to the audience using cultural signs and symbols. The communication object is conveyed to the audience by visual and aesthetic language consisting of signs and symbols, graphics, visit payment and other types of foundation image information (which the graphic designer traditionally chooses)." In this traditional context, the exchange of information takes place at the intersection of the communication object and how the audience perceives its aesthetic composition" (Bennett, 1386: 30). 


\section{Conclusion}

De-familiarization targets the audience's sensory perceptions, and for this purpose the designer uses a variety of visual communication techniques that help him to present the image realistically. Only then will the changes be tangible and understandable to the audience. This approach arouses the audience's curiosity by creating astonishment and surprise and forces the audience to make more efforts to decipher the meaning of the discourse. This makes the message more effective in his mind. Familiarizing graphic designers with de-familiarization strategies and techniques is the most important achievement of this research. Graphic designers will be able to use visual expression facilities to make an impact on the audience's mind and free interactive graphics from a purely commercial point of view by using unfamiliarity techniques in interactive graphics. The result of such a view is the emergence of creative and thought-provoking works in the field of society propaganda, which in addition to the power of influence, will place the audience's tastes at a high level of visual literacy.

\section{References}

Abedinifard, Morteza, 1388, work of art; regarding the existence of an object, Critical Quarterly, Nos. 7, 83 \& 84.

Afshar Mohajer, Kamran (2009), Graphics in the Publishing Industry, Samat Publications, Tehran.

Ahmadi, Babak (2003) Text structure and interpretation, Markaz Publishing, Tehran.

Bennett. A., R. Aglash (2007) Facilitating the emotional emotional participation of the audience in Creative Design Process, Robert Safarian, Artist Profession Magazine, No. 19, p.30.

Ejadi, Morteza (2004), Study of creative techniques in graphics, Islamic Azad University, Faculty of Art and Architecture, Department of Visual Communication, Degree M.Sc., Tehran

Fotouhi, Mahmoud (2007), Image Rhetoric, Sokhan Publications, Tehran.

Hosseini Khodadad, Seyed Hamid Ahmad Rousta, and Wahab Khalili Shojae (2010), Propaganda from Theory to Practice, Harufieh Publications, Tehran.

Nafisi, Azar (2007), De-Familiarization in Literature, Kayhan Farhangi, No. 2, p. 36.

Nowruzi Talab, Alireza (1989), Technique and Art, Journal of Honarhaye Ziba , No. 8, p.8.

Rousta, Ahmad, Khoyeh, Ali (2007), Advertising Techniques and Tactics, Sita Publishing, Tehran.

Samad Aghaei, Jalil (2001), Individual and Group Creativity Techniques, Tehran Public Management Training Center, Tehran.

Sasani, Farhad (2011), Metaphor of the basis of thinking and creating beauty, Surah Mehr, Tehran.

Shafi'i Kadkani, Mohammad Reza (1991), Poetry Music, Agah Publishing, Tehran.

Sullivan, Luke (2010) Creative Advertising, Setah Publications, Tehran.

Wells, William and Brent, John and Muriati, Sandra (2004), Business Advertising (Principles and Methods of Action), Missionary Publications, Tehran.

Young, James (2009), Art and Cognition, Academy of Arts, Tehran. 